\title{
DESTEMPERO E INSIPIDEZ
}

\section{Antonio Arnoni Prado}

RESUMO: O ensaio enfoca a presença crítica de Humberto de Campos no panorama da cultura brasileira do período, detendo-se em particular sobre o descompasso entre a visada generalizante e a ausência de contextualização propriamente literária acerca das obras e dos autores estudados.

PALAVRAS-CHAVE: Humberto de Campos; Crítica Biográfica; Modernismo

ABSTRACT: This essay focuses on the presence of Humberto de Campos criticism in the overview of Brazilian culture of his period. One observes in particular the divergence between his generalizing perspective and his absence of literary contextualization of the works and authors studied by him.

KEY WORDS: Humberto de Campos; Biographical Criticism; Modernism 
Entre janeiro de 1915 e 5 de dezembro de 1934, os registros que integram este Diário secreto de Humberto de Campos (1886-1934), ${ }^{1}$ se pouco ou quase nada remetem à configuração dos sinais mais vivos da ruptura que então animava a literatura e a cultura brasileira, menos ainda parecem alinhar-se ao espírito controverso das primeiras décadas do novo século.

Como o leitor verá, no horizonte estreito em que as entradas se sucedem, o que surpreende neste registro estático que se dirige à cultura é sobretudo o enfoque enclausurado com que Campos - aquém até mesmo da instância acadêmica a que então se destinava - se recusa a conceber o contraditório, mantendo sempre o olhar de cima, sem sequer desconfiar das manifestações cada vez mais vivas do espírito livre e da imaginação irreverente das vozes inventivas que aos poucos se vinham impondo ao peso imutável da tradição.

O mais grave é que o crítico faz praça de moderno ao concordar com João Ribeiro na redação de O Imparcial, por exemplo, sobre os excessos de vaidade e a falta de noção de tempo de um Rui Barbosa caudaloso, com aquele seu estilo "cacetíssimo", a abusar da paciência de seus ouvintes, "quando escreve ou quando fala". Ao contrário de Rui, ele, Humberto, é tido como menos empolado, basta ver - e é ele próprio que faz a citação - como Jackson de Figueiredo, em conversa com Félix Pacheco publicada na revista Brazílea o situa como "a personalidade que mais fortemente se afirma no momento atual", justamente - acrescenta - pela "simplicidade como expressão da perfeição", à frente de autores como Hermes Fontes, da Costa e Silva, Teófilo de Albuquerque e Gilka da Costa Machado.

Mas não é só. Além de Jackson, é em Alcides Maia que Humberto vai buscar outra indicação de suas virtudes literárias para ocupar uma cadeira na Academia Brasileira de Letras. E com merecimento mais do que legítimo: segundo Maia, bem à frente de um Óscar Lopes (a quem o próprio Humberto reconhecia merecer a escolha por já haver publicado quatro ou cinco livros, enquanto ele próprio só possuía uma única obra publicada). É que "tu tens um livro", argumentava Maia, [enquanto] Lopes tem quatro ou cinco volumes, mas não tem um livro".

O melhor caminho para chegar à Academia era o de seguir o exemplo de Olavo Bilac, conforme lhe sugeriu o amigo Macedo Soares: nada de "falar dos outros, nem bem

1 CAmpos, Humberto de. Diário secreto. Rio de Janeiro: Edições O Cruzeiro, 1954, 2 volumes, Coleção Geia de Temas Maranhenses, vol. 15; 2 ed.: São Luís: Instituto Geia, 2010. 
nem mal", mas procurar fazer com que, em suas crônicas, os outros é que falem sobre você. Assim é que deve ser, explicava Soares: como Bilac não "pusesse pedra no pedestal dos outros, e os outros pusessem no seu, ficou o seu mais alto do que o de todos os companheiros". E arrematava: "Segue o meu conselho... Não sejas tolo!".

Não que Óscar Lopes não tivesse verve para integrar a Academia, dada a desenvoltura com que se juntava aos amigos elegantemente enfileirados entre mesas e cadeiras num dos pontos seletos do Passeio, ao lado, por exemplo, de um Bastos Tigre montando guarda a um copo de uísque a avivar as ponderações de um fim de tarde qualquer.

É que Humberto não era de desistir. Prestava atenção a todos os detalhes que pudessem levá-lo ao Silogeu, e por isso frequentava lugares diferentes, conversando com todos os escritores, no luxo ou na miséria. Pois se nem mesmo recusou o níquel que lhe pedira, sem sequer agradecer, um Lima Barreto "cabeludo e imundo" que se arrastava trançando as pernas pela rua Sete de Setembro quase esquina da Gonçalves Dias.

Não! era preciso acabar com essa estória de continuarmos sendo uma colônia literária de Portugal, "não podemos nos submeter à pursódia de Lisboa unicamente por ser de Lisboa", dizia ele, retomando um desabafo intempestivo de João Ribeiro. É com esse espírito que Humberto "persegue" a convivência dos acadêmicos e, através deles, insiste em escavar a sua própria relevância.

Decisiva, nesse percurso, é a passagem por um ponto de referência incontornável: a casa de Coelho Neto, à qual Humberto comparece, convidado por dona Gabi, esposa do romancista. Na ocasião esta o informa de que, na véspera, Coelho Neto, em conversa com Goulart de Andrade, Leal de Souza e Martins Fontes, declarou - segundo ela, "por um dever de consciência" que os escritos de Humberto de Campos representavam, para o autor de Fogo fátuo, "a mais completa organização literária da sua geração". E o próprio Humberto, no rebrilhar de tanta lantejoula, e já então na Academia, não deixará jamais de transcrever as alusões com que o exaltavam, como na ocasião em que Afonso Celso assinalou pelas páginas do Jornal do Brasil "a extraordinária atividade mental que o traz sempre conhecedor de tudo quanto de mais interessante se publica no Brasil e no estrangeiro".

Terá sido mesmo? O leitor deste Diário secreto terá razões mais que suficientes para discordar. De uma primeira perspectiva, pela natureza dos princípios, em que não será exagero falar de uma espécie de anomia dos critérios em jogo. Um claro exemplo está na entrada que registra o falecimento do severo Carlos de Laet, o monarquista e católico praticante que acabou se transformando num dos publicistas mais dedicados à 
ética conservadora do antigo regime. Pois não é que Humberto o retrata, já aos oitenta anos, como amante de uma mulata do povo e pai de três mulatinhas, a mais velha de onze anos e a caçula de sete, meninas que se apresentavam de luto para o reinício das aulas na escola primária? "Com oitenta anos, aquele Catão tinha uma amante, uma enorme mulata de Botafogo!...” nos diz Humberto de Campos boquiaberto, como se surpreendesse o sisudo Laet num ato de molecagem impensável mesmo que na primeira mocidade.

E quanto a Oliveira Lima? Só a busca de um voto que o garantisse na Academia impôs que Humberto se encantasse com o ser monstruoso de rosto enorme e oval, a "boca polpuda sobre a qual desciam as duas guias do bigode chinês, as quais, arqueadas sobre a boca, pareciam mais as duas asas de um pássaro pequeno que lhe quisesse entrar pelo nariz". E que dizer da entrada de 7 de maio de 1928 em que Humberto confessa o seu horror à mulher negra, afirmando que se sentiria desonrado para o resto de sua vida ("e sentiria engulhos até a hora de minha morte") se, "arrastado pelo instinto, realizasse um ato amoroso com uma mulher de cor"? Porém há mais: ao nos afirmar que os fios encaracolados do cabelo da mulher negra, "retorcidos, em espiral" dão-lhe a "impressão de coisa imunda", o Autor vai ao extremo de advertir que "o homem branco que beijasse a cabeça de uma preta devia... lavar a boca sessenta vezes por dia, durante sessenta anos".

Não, leitor, não se trata de uma expansão ficcional. As marcas do preconceito racial nas elucubrações do narrador Humberto de Campos, se primam pela arrogância e o disparate, parecem projetar-se em certo destempero ideológico tão comum no escritor secundário com ânsia de ascensão intelectual frente a um mundo que ele está longe de compreender. Tão lamentável quanto os seus preconceitos só o cabotinismo de Gilberto Amado, que, como refere adiante uma citação de Afrânio Peixoto, era um tipo "capaz de matar o próprio filho e dá-lo aos cães, contanto que se falasse no seu nome!".

Exageros à parte, é esse um tema candente nas anotações deste Diário secreto, ele mesmo uma espécie de recorte deslumbrado com os múltiplos artifícios com que um João do Rio, por exemplo, se consumia em busca de criar um brilho próprio que o projetasse nesse cotidiano de lantejoulas, ainda que com isto - assinala Campos - sacrificasse "os seus brios de homem, fazendo constar que o horizonte, a exemplo do Humberto de Campos obcecado pela miragem da Academia, o alvo maior era o orgulho de parecer ilustre, de ser discutido, comentado, citado". "Que o insultassem, que o injuriassem, mas que não o esquecessem”, como aliás queria o próprio João do Rio. 
É verdade que as estripulias sexuais no imaginário grã-fino de Paulo Barreto convivem, no livro de Humberto, com as dolorosas confissões de uma pobre moça da periferia, que revela ao seu parceiro de lupanar ser ela a responsável pelo sustento da família e pelo pagamento do aluguel da casa em que moram a mãe e os irmãos, apesar de ela mesma ser obrigada a viver num quarto de aluguel "em casa alheia", por julgarem os parentes que ela não devia viver com eles por ser "a vergonha da família”.

Mas há cenas menos edificantes a deslustrar o anedotário acadêmico, como o episódio narrado uma tarde por Coelho Neto na sala de espera do "Petit-Trianon", em presença do poeta Alberto de Oliveira, com José do Patrocínio no centro do relato. Convidado por Campos da Paz a ir a uma famosa cartomante instalada na Rua da Carioca ("uma espanhola gorducha, de meia-idade, com um buço forte no lábio superior"), a mulher se volta espantada para um Patrocínio intrigado e lhe diz, depois de embaralhar as cartas:

“- Oh! Belo dia! Grande dia! Muito povo... música... muita alegria... gente na rua... E o senhor no meio..."

E de repente, apontando para o chão:

“- "Depois... afunda... vai para o fundo... para baixo!" Coelho Neto é quem conclui: "Era o Treze de Maio! Feita a Abolição, Patrocínio afundou.

Com Patrocínio no fundo do poço, é Tristão de Athayde quem recebe a próxima saraivada, ele, um autor que gasta mais de três contos de réis em livros, mas um crítico - segundo Humberto de Campos - incapaz de escrever em ordem sobre os conteúdos que lê. "Ao deparar com um artigo seu, vem-me à lembrança, não sei por quê, o quadro sinistro de um grande edifício moderno desmoronando num incêndio, tudo afinal inaproveitável."

E Tristão de Athayde não é a única vítima do destempero antimoderno que anima a insipidez das opiniões críticas de Humberto de Campos. Prudente de Morais Filho, por exemplo, lido por Campos, também se vê repentinamente injuriado em seu gesto nobre de tentar publicar o "diário" crítico do amigo Carlos Peixoto, ex-presidente da Câmara, recentemente falecido: autorizado pelo pai do amigo morto, topa com uma passagem inesperada do diário de Peixoto (mas certamente significativa aos olhos insípidos de Humberto de Campos): "Esteve hoje em minha casa o Prudentinho... Que besta!...”. 
E que dizer da descrição que nos deixou do crítico José Veríssimo, para ele "um solitário amargo, um eremita selvagem", cuja barba lhe nascera "intratável como um molho de capim numa pedra", a ele, Veríssimo, a quem ademais estranhava "por sua voz desafinada, com transições do fino para o roufenho... com seus dentes superiores de carnívoro voltados para dentro", fazendo com que as palavras ressoassem quase como "um grasnido de corvo". Mas mesmo assim Humberto o visitava em sua casa (ah! O que não vale a Academia!), onde sempre era bem recebido a ponto de Alberto de Oliveira lhe confessar uma vez que o autor da História da Literatura Brasileira, sempre que se referia a Humberto, o fazia "com muita afeição".

Não é o caso de relembrar aqui a dureza com que Campos ironiza a presença de um Silva Ramos na Academia, ao considerá-lo "um pedaço de deserto, árido, seco e abandonado, que, em quase oitenta anos, deu apenas duas pequenas moitas de capim". Ou mesmo a forma com que desfigura a imagem consagrada do príncipe D. Pedro em sua jornada pelos lados do Ipiranga, marcada - segundo Campos - não apenas por ignorar a tradição do brado histórico de "Independência ou Morte", que o celebrizou, mas em particular por suas constantes fugas para o mato "a fim de satisfazer as exigências de um desarranjo intestinal".

Na verdade, o que marca as anotações deste Diário secreto é sobretudo a variedade esdrúxula de uma alternância de tons quase sempre desconexos que, ao longo da travessia, não chegam a nos revelar de que modo o Autor afinal concebe o papel da literatura e dos literatos do Brasil de seu tempo, a ponto mesmo de perder-se em meio às circunstâncias históricas do momento cultural de que faz parte, que o fazem ora tropeçar no esforço inútil de superar o formalismo capenga que contava buscar na Academia, ora propor soluções descabidas ao panorama político (como no caso do intento separatista dos gaúchos), ora ainda rastrear imagens simplistas acerca de algumas personalidades, a exemplo do que ocorre com Juarez Távora, comparado no livro a "uma donzela de dezesseis anos levada, inocentemente, depois da meia-noite, a uma casa de prostituição".

Poderíamos citar diversos momentos dessas simplificações intempestivas, em que um Graça Aranha reaparece pensando numa reconciliação com a Academia; em que o crítico João Ribeiro é surpreendido pela tentação de trocar a crítica literária pelo dinheiro; em que o poeta Ronald de Carvalho é literalmente reduzido a "um espírito de segunda ordem"; e em que o próprio Humberto de Campos, como que se lamentando por não ter o estilo e a verve de um artista como Goethe, justifica o próprio destino ao comparar a sorte ingrata de haver sido um pobre órfão mergulhado na miséria, com 
o destino oposto do gênio alemão, que desfrutou de uma infância feliz e tranquila de menino rico, cercado de livros e educado por bons professores, num "ambiente aristocrático e artístico".

É no contexto dessas elucubrações arrevesadas e sem critério que chegamos por vezes a ver com bons olhos que o melhor destino para a sorte de um Diário secreto como este talvez seja o de permanecer secreto, sempre fechado sobre si mesmo, na prateleira mais elevada da estante em que o depositarem.

Antonio Arnoni Prado é Professor Titular da Universidade Estadual de Campinas 